\title{
Diagnostic aspiration of an iatrogenic hydrothorax following subclavian catheterization
}

\author{
M.J. Steiger and A.G. Morgan \\ Department of Renal Medicine, City Hospital, Nottingham NG5 IPB, UK.
}

Summary: Central venous catheterization is not without hazard. Inadvertent placement in the pleural space can occur without the development of a pneumothorax and pressure measurements may appear misleadingly normal. This case report illustrates an effective method of diagnosing and draining an iatrogenic hydrothorax which resulted in this way.

\section{Introduction}

Subclavian venepuncture as a venous access route was originally described by Aubaniac 38 years ago. The technique became more popular after the description by Wilson et al. in $1962^{2}$ of central venous pressure measurement through subclavian vein catheters. Central venous pressure (CVP) monitoring as a guide to diagnosis and therapy in patients with hypovolaemia, hypotension, rapidly changing blood volume and renal failure is widely accepted.

We report an original, effective method of diagnosing and draining an iatrogenic hydrothorax following subclavian catheter puncture of the pleura, in whom initial catheter position was thought to be satisfactory.

\section{Case report}

A 61 year old woman with insulin-dependent diabetes mellitus, was referred for further management of acute renal failure. She had been admitted 20 hours earlier to another hospital with diarrhoea and vomiting of one week's duration. Initial investigation had shown a metabolic acidosis ( $\mathrm{pH} 7.26)$ and uraemia (plasma urea $29.6 \mathrm{mmol} / \mathrm{l}$, creatinine $841 \mu \mathrm{mol} / \mathrm{l})$. A Vygon 16 gauge catheter was 'inserted easily' via an infraclavicular approach into the right subclavian vein. The CVP was recorded as $+4 \mathrm{~cm}$ water, increasing to $+5 \mathrm{~cm}$ after instillation of $200 \mathrm{ml}$ of normal saline. A chest $\mathrm{X}$-ray (Figure 1) suggested that the catheter was lying in the superior vena cava, although the tip of the catheter could not be accurately identified. The

Correspondence and present address: M.J. Steiger, M.R.C.P., Clinical Research Fellow, Department of Clinical Neurology, Institute of Neurology, Queen Square, London WCIN 3BG, UK.

Accepted: 13 March 1990

patient remained oliguric, and 9 hours after insertion of the subclavian catheter, widespread right $\mathrm{N}$ sided inspiratory crackles were heard. The CVP $\cong$ was $+7.5 \mathrm{~cm}$ water and the chest X-ray was repeated (Figure 2). Because oliguria had persisted despite having received 3.2 litres of fluid intravenously she was referred for possible haemodialysis.

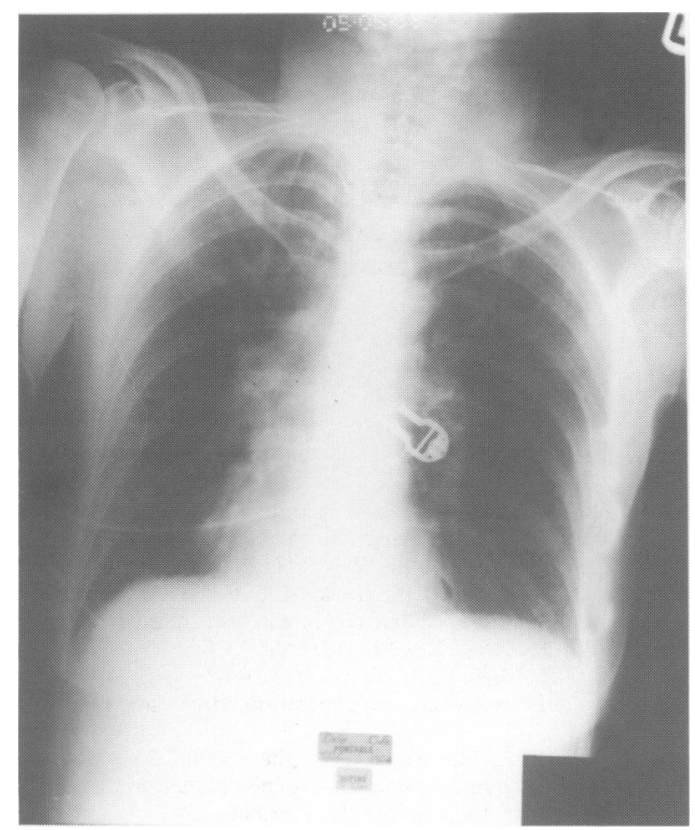

Figure 1 Chest $\mathrm{X}$-ray following right subclavian catheterization. Most of the catheter appears to be lying in the position of the superior vena cava, but the position of the tip cannot be clearly identified. 


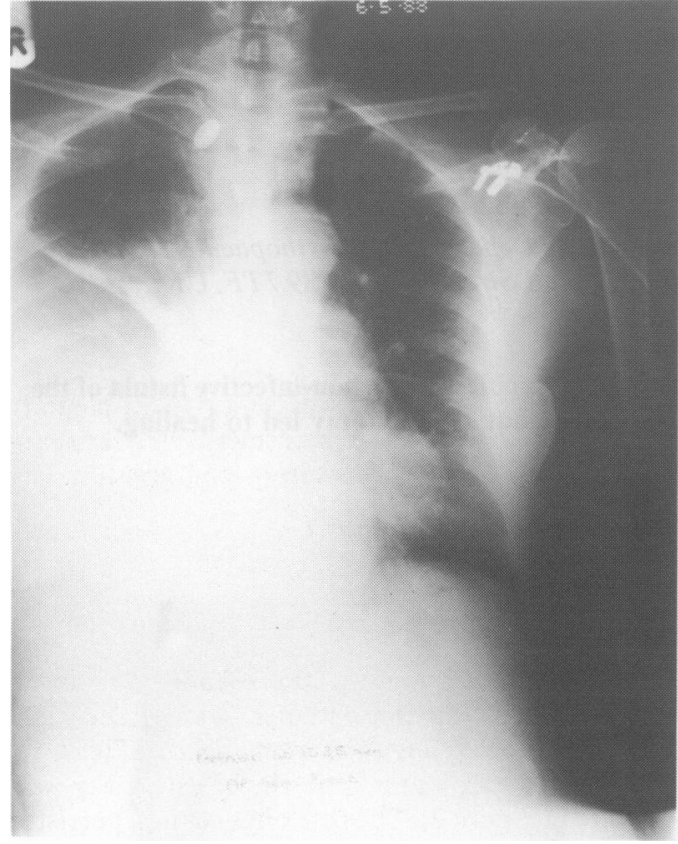

Figure 2 Chest X-ray 9 hours later showing a right pleural effusion. Catheter tip cannot be identified.

On arrival there were peripheral signs of salt and water depletion, but there was a right sided pleural effusion. The CVP was seen to move only sluggishly with respiratory excursions. On aspirating the subclavian catheter to assess patency, clear fluid was obtained and a total of 2.4 litres was removed with resolution of the right hydrothorax.

Resiting of venous access allowed correction of salt and water depletion and recovery from prerenal uraemia.

\section{References}

1. Aubianiac, R. Une novelle voie d'injection ou de ponction veineuse: la voie sous-claviculaire (veine sous-claviere, tronc brachiocephalique). Semin Hop Paris 1952, 28: 3445-3447.

2. Wilson, J.N., Grow, J.B., Demong, D.V., Prevedel, A.E. \& Owens, J.C. Central venous pressure in optimal blood volume maintenance. Arch Surg 1962, 85: 563-578.

3. Smith, B.E., Modell, J.H., Gaub, M.L. \& Moya, F. Complications of subclavian vein catheterization. Arch Surg 1965, 90: 228-229.

4. Feliciano, D.V., Mattox, K.L., Graham, J.M., Beall, A.C. \& Jordan, G.L. Major complications of percutaneous subclavian vein catheters. Am J Surg 1979, 138: 869-874.

\section{Discussion}

The insertion of central venous access catheters for central venous pressure monitoring is not without complication, but most reported problems are relatively minor and include pneumothorax, subclavian artery puncture and improper positioning. ${ }^{4}$ Many of the complications that arise from use of CVP catheters are due to poor technique, ${ }^{5}$ and may be reduced by supervision of the inexperienced along with awareness of potential hazards of insertion and monitoring. When uncertain of the exact site of the catheter tip, a small amount of dye may help to define its location.

Iatrogenic hydrothorax following central cannulation is reported sporadically, ${ }^{4-7}$ and may occur when the tip of the catheter is not seen on the chest $X$-ray performed after insertion. Under these circumstances the X-ray should be repeated. When the site of the tip remains uncertain, a small amount of dye may help in defining its location. The pleura is easily entered because it is close to the subclavian vein $^{3}$ and manometric measurement of CVP may not show that this has happened since the pressure may continue to rise and fall with respiratory movements. ${ }^{8}$ However, following perforation into the pleural cavity the negative phase with ventilation may fail to improve despite volume replacement. Lack of clinical response to fluids or drugs instilled down the catheter, or the development of respiratory difficulties should suggest that there has been extravascular placement. Any sudden or unexplained deterioration in the patient with a central venous catheter should arouse suspicion of possible catheter perforation of a central vein. This may occur several hours following catheter insertion if the catheter lies against the vein wall. ${ }^{5}$

This case emphasizes the need for vigilance in central venous catheterization and illustrates the usefulness of aspiration in assessing catheter patency and positioning.

5. Rudge, C.J., Bewick, M. \& McColl, I. Hydrothorax after central venous catheterization. $\mathrm{Br}$ Med J 1973, 3: 23-25.

6. Aulenbacher, C.E. Hydrothorax from subclavian vein catheterization. JAMA 1970, 214: 372.

7. Demey, H.E., Cloemont, L.J., Hartoko, T.J., Roodnooft, A.-M.I., Ysebaert, D.Y. \& Bossaert, L.L. Venopulmonary fistula: a rare complication of central venous catheterization. JPEN J Parenter Enteral Nutr 1987, 11: 580-582.

8. Venkateswaran, V. Fallacy of clinical confirmatory signs in internal jugular catheterization: a case report. Med J Malaysia 1986, 41: 374-376. 